\title{
Experimental assessment of the influence of beam hardening filters on image quality and patient dose in volumetric 64-slice X-ray CT scanners
}

\author{
Mohammad Reza Ay a,b,c,*, Abolfazl Mehranian ${ }^{d}$, Asghar Maleki e, \\ Hossien Ghadiri ${ }^{\text {a,b }}$, Pardis Ghafarian ${ }^{\mathrm{f}, \mathrm{g}}$, Habib Zaidi ${ }^{\mathrm{d}, \mathrm{h}, \mathrm{i}}$
}

\footnotetext{
${ }^{a}$ Department of Medical Physics and Biomedical Engineering, Tehran University of Medical Sciences, Tehran, Iran

${ }^{\mathrm{b}}$ Research Center for Science and Technology in Medicine, Tehran University of Medical Sciences, Tehran, Iran

${ }^{c}$ Research Institute for Nuclear Medicine, Tehran University of Medical Sciences, Tehran, Iran

'Geneva University Hospital, Division of Nuclear Medicine and Molecular Imaging, CH-1211 Geneva, Switzerland

${ }^{\mathrm{e}}$ Faculty of Physics and Nuclear Engineering, Amir Kabir University of Technology, Tehran, Iran

f Telemedicine Research Center, NRITLD, Masih Daneshvari Hospital, Shahid Beheshti University of Medical Sciences, Tehran, Iran

${ }^{g}$ Chronic Respiratory Disease Research Center, NRITLD, Masih Daneshvari Hospital, Shahid Beheshti University of Medical Sciences, Tehran, Iran

${ }^{\mathrm{h}}$ Geneva University, Geneva Neuroscience Center, $\mathrm{CH}-1211$ Geneva, Switzerland

i Department of Nuclear Medicine and Molecular Imaging, University Medical Center Gronigen, University of Groningen, 9700 RB Groningen, Netherlands
}

Received 16 July 2011; received in revised form 8 February 2012; accepted 26 March 2012 Available online 25 April 2012

\section{KEYWORDS \\ $\mathrm{X}$-ray CT; \\ X-ray filters; \\ Beam hardening; \\ Image quality; \\ Patient dose}

\begin{abstract}
Beam hardening filters have long been employed in X-ray Computed Tomography (CT) to preferentially absorb soft and low-energy X-rays having no or little contribution to image formation, thus allowing the reduction of patient dose and beam hardening artefacts. In this work, we studied the influence of additional copper $(\mathrm{Cu})$ and aluminium (Al) flat filters on patient dose and image quality and seek an optimum filter thickness for the GE LightSpeed VCT 64-slice CT scanner using experimental phantom measurements. Different thicknesses of $\mathrm{Cu}$ and Al filters (0.5-1.6 mm Cu, 0.5-4 mm Al) were installed on the scanner's collimator. A planar phantom consisting of 13 slabs of $\mathrm{Cu}$ having different thicknesses was designed and scanned to assess the impact of beam filtration on contrast in the intensity domain (CT detector's output). To assess image contrast and image noise, a cylindrical phantom consisting of a polyethylene cylinder having 16 holes filled with different concentrations of $\mathrm{K}_{2} \mathrm{HPO}_{4}$ solution mimicking
\end{abstract}

\footnotetext{
* Corresponding author. Department of Medical Physics and Biomedical Engineering, Tehran University of Medical Sciences, Tehran, Iran. Tel.: +9821 66466383; fax:+98 2166402729 .

E-mail address: mohammadreza_ay@tums.ac.ir (M.R. Ay).
} 
different tissue types was used. The GE performance and the standard head CT dose index (CTDI) phantoms were also used to assess image resolution characterized by the modulation transfer function (MTF) and patient dose defined by the weighted CTDI. A $100 \mathrm{~mm}$ pencil ionization chamber was used for CTDI measurement. Finally, an optimum filter thickness was determined from an objective figure of merit (FOM) metric. The results show that the contrast is somewhat compromised with filter thickness in both the planar and cylindrical phantoms. The contrast of the $\mathrm{K}_{2} \mathrm{HPO}_{4}$ solutions in the cylindrical phantom was degraded by up to $10 \%$ for a $0.68 \mathrm{~mm} \mathrm{Cu}$ filter and $6 \%$ for a $4.14 \mathrm{~mm}$ Al filter. It was shown that additional filters increase image noise which impaired the detectability of low density $\mathrm{K}_{2} \mathrm{HPO}_{4}$ solutions. It was found that with a $0.48 \mathrm{~mm}$ Cu filter the $50 \%$ MTF value is shifted by about $0.77 \mathrm{lp} / \mathrm{cm}$ compared to the case where the filter is not used. An added Cu filter with approximately $0.5 \mathrm{~mm}$ thickness accounts for $50 \%$ reduction in radiation-absorbed dose as measured by the weighted CTDI. The FOM results indicate that with an additional filter of $0.5 \mathrm{~mm}$ Cu or minimum $4 \mathrm{~mm} \mathrm{Al}$, a good compromise between image quality and patient dose is achieved for CT images acquired at tube voltages of 120 and $140 \mathrm{kVp}$. The results seem to indicate that an optimum filter for high $\mathrm{kVp}$ acquisitions, routinely used in cardiovascular imaging, should be $0.5 \mathrm{~mm}$ copper or $4 \mathrm{~mm}$ aluminium minimum.

(c) 2012 Associazione Italiana di Fisica Medica. Published by Elsevier Ltd. All rights reserved.

\section{Introduction}

Since its introduction in clinical setting, $X$-ray Computed Tomography (CT) has experienced considerable technical advances both in data acquisition and image reconstruction and has emerged as a leading cross-sectional diagnostic imaging technique of choice in clinical setting. Taking advantage of multi-detector row technology and scan speeds as fast as $0.3 \mathrm{~s}$ [1], CT imaging has further found new applications in cardiovascular imaging [2]. Compared to other imaging modalities, X-ray CT delivers relatively high radiation doses to patients to provide acceptable diagnostic quality images $[3,4]$. This has provoked a growing concern on patient dose and called for continuous efforts in developing dose reduction and optimization procedures and maintaining radiation exposures as low as reasonably achievable [5].

As polychromatic X-ray beams used during CT imaging pass through a patient, soft and low energy $X$-rays, which are of little importance in image formation, are preferentially absorbed to a great extent compared to high-energy photons. A consequence of this selective absorption is the increase in patient's absorbed dose and non-linear increase in the beam's average energy, which is often referred to as beam hardening effect [6]. As a result, the total attenuation of X-rays and therefore the associated log-processed transmission data will no longer be a linear function of tissue thickness. The most widely used Filtered backprojection (FBP) algorithms in $\mathrm{CT}$ reconstruction assume a linear propagation model for the detected photons and as such fail to consider the non-linear beam hardening effect [7]. Consequently, the reconstructed images exhibit cupping artefacts and reduced CT numbers behind bony structures and streak artifacts around metallic objects [8-11]. These artefacts may mimic or obscure pathologic lesions, rendering the interpretation of CT images complicated and leading to equivocal findings $[12,13]$. The polychromaticity of X-ray beams therefore not only increase patient dose but also induce beam hardening artefacts. Hence, there is a need for taking appropriate measures toward concomitant patient dose reduction and beam hardening correction (BHC).
Various schemes have been suggested for BHC in FBP images including pre-processing of projection data [14-17], post-processing of the reconstructed images [18-22], dualenergy imaging [23-25] and physically pre-filtering the incident X-ray spectra $[14,15]$. Pre-processing assumes that all soft tissues have the same hardening properties as water and scales the projection data by those where beam hardening had not occurred [17]. This approach which is often referred to as water or linearization correction works well with soft tissues but fails in the presence of bony and high-density materials. In post-processing, the problem of bones is fairly tackled, since the contribution made by bone to projection data is determined in a reconstructionsegmentation process and appropriate correction is applied through linearization [18]. In the dual-energy technique proposed by Alvarez and Macovski [25], linear attenuation coefficients are decomposed into photoelectric and Compton scatter components. Therefore, CT images can in principle be generated at any energy, free from beam hardening. Dual-energy CT imaging, however, requires two acquisitions with two different energies, which compromises its use in a clinical setting owing to increased patient dose. Another approach for BHC is to physically pre-filter the $\mathrm{X}$-ray spectra prior to reaching the patient using additional beam hardening filters. The rationale behind this approach is that beam hardening would not occur if monoenergetic X-ray sources are used for CT data acquisition [7]. Additional filters thus harden the radiation beam by absorbing soft X-ray photons, so that a more homogenous beam is utilized for imaging. Furthermore, specially designed filters known as beam shapers (e.g. bow tie filter) are also used in CT scanners to shape the $\mathrm{x}$-ray beam to deliver dose with appropriate spatial distribution. As consequence of pre-filtering, both beam hardening effect and patient's absorbed dose are intrinsically reduced, however, as a compromise, statistical noise or quantum mottle is increased, which in turn impairs image quality and low-contrast detectability [26].

Statistical noise governed by photon counting statistics tends to increase as pre-filtering decreases the number of photons available for $\mathrm{CT}$ image formation. This has spurred 
many studies on optimizing pre-filtering using different filter materials and thicknesses to reach a compromise between image quality and patient dose. Szulc and Judy [27] indicated that filter materials with an atomic number from 29 to 40 are optimum for CT imaging and concluded that a minimum of $4 \mathrm{~mm}$ aluminium (Al) filtration was required to achieve an optimum level of dose performance at $120 \mathrm{kVp}$. In a study on spectrally equivalent filters in the diagnostic energy range, Jennings [28] indicated that copper (Cu) beam hardening filters are preferable to aluminium filters as they are about $10 \%$ more efficient. Compared to Al filters, Cu filters have a higher photoelectric absorption than Compton scatter which makes it as an efficient filter for diagnostic radiology [29]. In conventional projection radiology, beam filtration is widely used. Kohn et al. [30] determined experimentally that for the least X-ray tube loading, a compound filter of $0.1 \mathrm{~mm}$ $\mathrm{Cu}$ and $2 \mathrm{~mm} \mathrm{Al}$ yields the lowest entrance skin exposure compared to a filter of $2 \mathrm{~mm} \mathrm{Al}$. In a study on optimisation of $\mathrm{Cu}$ filter thickness for contrast-enhanced projection radiology, Morrell et al. [31] reported that $0.3 \mathrm{~mm}$ of $\mathrm{Cu}$ reduces entrance surface dose rate by $56 \%$ without substantially degrading image contrast. Current generation CT scanners typically employ a beam filtration between $1 \mathrm{~mm}$ and $3 \mathrm{~mm}$ $\mathrm{Al}$ and an additional filtration of $0.1 \mathrm{~mm} \mathrm{Cu}$, giving a total beam filtration of between $5 \mathrm{~mm}$ and $6 \mathrm{~mm}$ Al. However, there are some newer scanners that operate with an added filtration of approximately $0.2 \mathrm{~mm} \mathrm{Cu}$, resulting in a total beam filtration of between $8 \mathrm{~mm}$ and $9 \mathrm{~mm} \mathrm{Al}$, and sometimes even up to $12 \mathrm{~mm}$ Al quality-equivalent filtration [32].

With advances in multi-detector row technology, there is a rapid shift toward multislice and volumetric CT acquisitions particularly targeted for cardiovascular imaging. Multislice CT and associated technical advances have markedly influenced radiation dose requirements and the way dose reduction and optimization procedures are practiced in the context of CT imaging [33]. This emphasizes the need for more dedicated, scanner-oriented optimization techniques so as to achieve diagnostically acceptable images with the lowest possible patient dose. In fact, recent advances in dose reduction strategies address the issue of radiation optimization through beam collimation and filtration, automatic tube current modulation, efficient detector configuration and advanced image reconstruction algorithms [33,34]. Along these lines, we aimed at optimizing experimentally $X$-ray beam hardening filters for an advanced multislice CT scanner and quantifying its influence on image quality and dose delivered to patients. We also define a figure of merit (FOM) to seek an optimum filter capable of minimizing patient dose without markedly impairing image quality.

\section{Materials and methods}

\section{The CT scanner}

CT imaging was performed using the 64-slice LightSpeed VCT scanner (GE Healthcare Technologies, Waukesha, WI). This VCT system equipped with V-Res detector technology acquires 64 channels across $40 \mathrm{~mm}$ of the subject in less than $0.4 \mathrm{~s}$. The V-Res detector consists of GE's patented Hilight scintillator coupled to a backlit-configured diode and the Volara data acquisition system capable of acquiring 58,368 channels simultaneously. Contrary to frontlit, the backlit configuration makes the diodes very scalable, thereby higher signal isolation and better image resolution is achievable. The scanner makes use of the Performix Pro $X$-ray tube which delivers up to $800 \mathrm{~mA}$ and has an inherent filtration of $3.25 \mathrm{~mm}$ Al plus $0.1 \mathrm{~mm} \mathrm{Cu}$ at $140 \mathrm{kVp}$. For Xray beam filtration, the LightSpeed VCT provides three types of filters including a flat filter, a bowtie beam shaping filter with three sizes - small, medium and large - optimized over the full range of patient sizes, from paediatric/ head $(<25 \mathrm{~cm})$ to large-body $(35-50 \mathrm{~cm})$ and a cardiac filter mode for cardiovascular imaging studies [35].

\section{Additional filters and phantoms}

To determine an optimum additional flat filter in the LightSpeed VCT scanner, several copper (Cu) and aluminium (Al) filters with dimensions of $4 \mathrm{~cm} \times 10 \mathrm{~cm}$ and thicknesses of $0.15-1.61 \mathrm{~mm} \quad(\mathrm{Cu})$ and $0.53-4.14 \mathrm{~mm}$ (Al) were prepared and in turn installed on the scanner's collimator aperture. Table 1 presents the thicknesses of the filters used for CT imaging of the phantoms studied in this work. Two in-house phantoms including a planar and a cylindrical phantom were designed for evaluating the influence of beam filtration on contrast in intensity domain (CT detector's output) and in image domain (CT numbers). The planar phantom consists of 13 slabs of Copper fixed on a foam and $5 \mathrm{~mm}$ apart from each other (Fig. 1a). The slabs have a dimension of $40 \mathrm{~cm} \times 12.5 \mathrm{~cm}$ and thicknesses of $0.13-1.31 \mathrm{~mm}$. The specified $\mathrm{Al}$ and $\mathrm{Cu}$ filters for this phantom (Table 1) were in turn installed and after centring the phantom, a CT radiograph (scout view) was acquired using the following acquisition parameters: tube potentials of 120 and $140 \mathrm{kVp}, 200 \mathrm{~mA}$ tube current, $2 \mathrm{~s}$ scan time, $5 \mathrm{~mm}$ slice thickness and small bowtie filter. The $25 \mathrm{~cm}$ diameter cylindrical polyethylene phantom composed consists of 16 cylindrical holes $(2 \mathrm{~cm}$ diameter) on its perimeter and four holes $(0.5 \mathrm{~cm}$ in diameter) nearby its centre plus a central hole for pencil dosimeter placement (Fig. 1b). The central holes were empty whereas the peripheral holes were filled with different concentrations of $\mathrm{K}_{2} \mathrm{HPO}_{4}$ solution ranging from $0 \mathrm{~g} / \mathrm{cc}$ (only water) to $1.80 \mathrm{~g} / \mathrm{cc}$ to simulate soft tissue and bones with different densities (Table 2). The phantom was scanned for different

Table 1 Aluminium (Al) and copper (Cu) filter thicknesses (in $\mathrm{mm}$ ) used for the studied phantoms.

\begin{tabular}{lll}
$\begin{array}{l}\text { Planar/cylindrical } \\
\text { phantom }\end{array}$ & $\begin{array}{l}\text { GE performance/CTDI } \\
\text { phantom }\end{array}$ \\
\cline { 1 - 2 } $\mathrm{mm} \mathrm{Al}$ & $\mathrm{mm} \mathrm{Cu}$ & \\
\hline 0.53 & 0.15 & 0.15 \\
1.06 & 0.28 & 0.28 \\
2.60 & 0.48 & 0.48 \\
4.14 & 0.68 & 0.68 \\
& & 0.75 \\
& & 1.40 \\
& & 1.61 \\
\hline
\end{tabular}



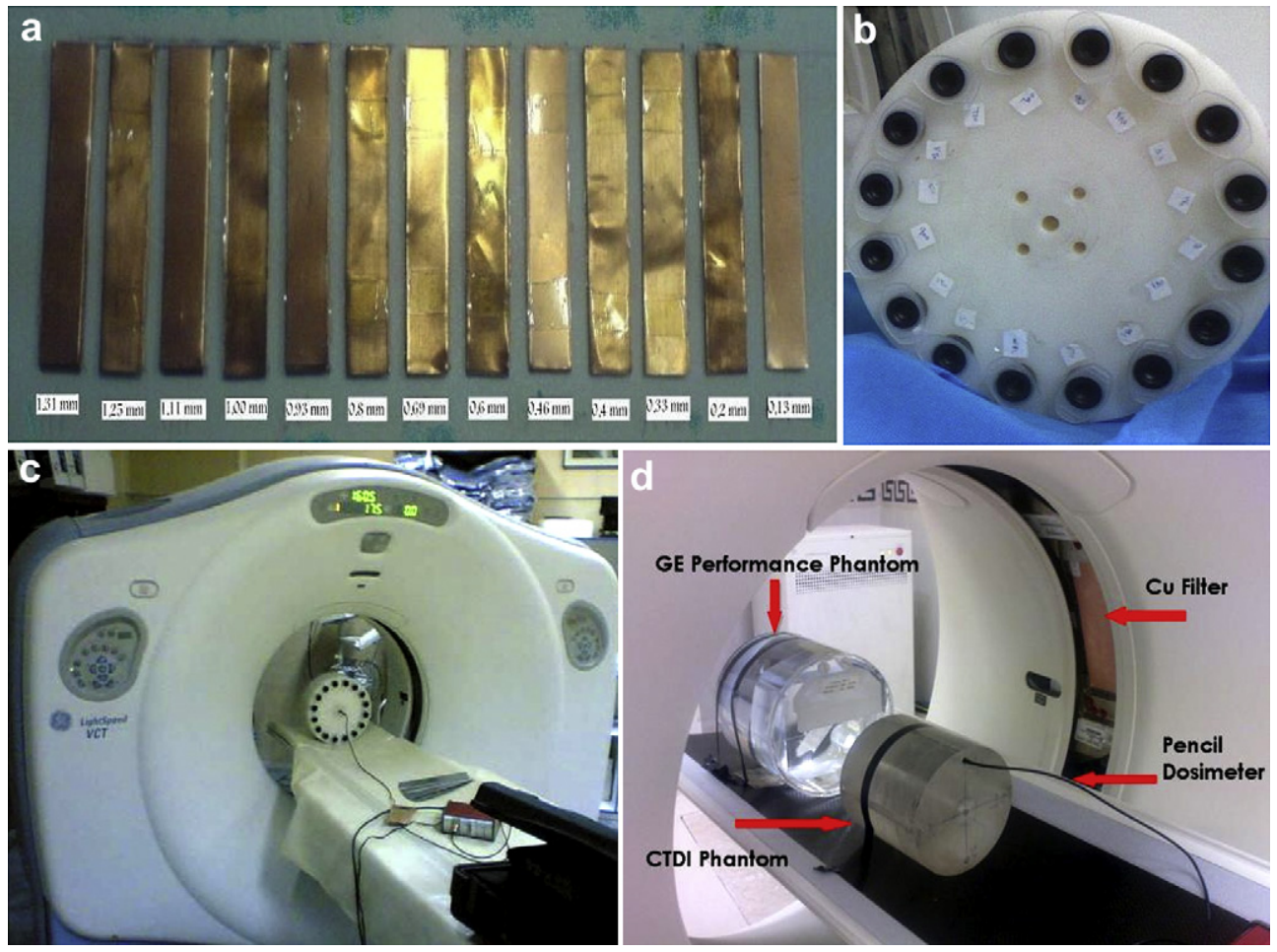

Figure 1 Photographs of phantoms and experimental setup used. (a) The planar phantom and (b) the cylindrical phantom designed for intensity and image contrast assessment, respectively. (c) The cylindrical phantom centred in the CT scanner with a pencil dosimeter. (d) The GE performance and CTDI phantoms, pencil dosimeter and copper filter installed in the collimator.

thicknesses of $\mathrm{Al}$ and $\mathrm{Cu}$ filters (see Table 1) and tube potentials of 120 and $140 \mathrm{kVp}, 200 \mathrm{~mA}$ tube current, $2 \mathrm{~s}$ scan time, $1.25 \mathrm{~mm}$ slice thickness and small bowtie filter. Fig. 1c shows the cylindrical phantom and its setup for experimental measurements.

Table 2 Concentration and density of $\mathrm{K}_{2} \mathrm{HPO}_{4}$ solution in the 16 holes of the cylindrical phantom used to mimic different biological tissues.

\begin{tabular}{lll}
\hline No. Solution & Concentration $(\mathrm{g} / \mathrm{cc})$ & Density $\left(\mathrm{g} / \mathrm{cm}^{3}\right)$ \\
\hline 1 & $0.00^{\mathrm{a}}$ & 1.00 \\
2 & 0.12 & 1.08 \\
3 & 0.18 & 1.12 \\
4 & 0.24 & 1.16 \\
5 & 0.30 & 1.20 \\
6 & 0.36 & 1.25 \\
7 & 0.48 & 1.33 \\
8 & 0.54 & 1.37 \\
9 & 0.60 & 1.41 \\
10 & 0.66 & 1.45 \\
11 & 0.72 & 1.49 \\
12 & 0.84 & 1.57 \\
13 & 0.90 & 1.61 \\
14 & 1.20 & 1.82 \\
15 & 1.50 & 2.02 \\
16 & 1.80 & 2.22 \\
\hline a Only water. & &
\end{tabular}

The GE performance phantom generally used for quality control and spatial resolution measurements was employed for assessing the impact of pre-filtering on overall image quality and the scanner's modulation transfer function (MTF). The phantom is composed of a water-filled cylindrical Plexiglas shell $(20.3 \mathrm{~cm}$ inner and $21.6 \mathrm{~cm}$ outer diameter) divided into three different sections. The first section contains some patterns for measuring spatial resolution, slice thickness and laser light alignment. The patterns for spatial resolution include 6 groups of 5 linepairs corresponding to spatial frequencies of $3,4,5,6,7$ and $8.5 \mathrm{lp} / \mathrm{cm}$. The second section includes low contrast resolution patterns whereas the third one contains water for the purpose of noise measurement (Fig. 1d). Acquisition parameters were similar to those used for the cylindrical phantom study. The method adopted for experimental measurement of the MTF, referred to as the standard deviation (SD) method, is based on calculation of the SD of $\mathrm{CT}$ numbers in different regions of a phantom followed by determination of modulation coefficient. Three regions of interest (ROI) were selected for each specific spatial frequency [37].

To estimate patient dose reduction following prefiltering, the standard head CTDI phantom consisting of a polymethyl methacylate (PMMA) cylinder $(15 \mathrm{~cm}$ length and $16 \mathrm{~cm}$ diameter) was used. It contains five probe holes, one located in the centre and four around the perimeter, $90^{\circ}$ apart from each other and $1 \mathrm{~cm}$ below the surface (Fig. 1d). For CTDI measurements, we used the DCT10-RS ionization chamber equipped with the Barracuda system (RTI Electronics, Inc., Sweden). This pencil dosimeter has 
an active length of $100 \mathrm{~mm}$ and is especially intended for CTDI measurement in air or within the phantom. As presented in Table 1, different thicknesses of $\mathrm{Cu}$ filter were used for CTDI measurement using the same acquisition parameters used for the cylindrical phantom.

\section{Assessment strategy}

\section{Image quality evaluation}

Image quality in $\mathrm{CT}$, as in all imaging modalities, is principally characterized by image contrast, spatial resolution and noise. Image contrast is the difference in the image gray-scale between closely adjacent regions and results essentially from subject contrast. Subject contrast, that is the differential attenuation of $X$-ray photons within different tissue types, is often defined as follows:

$C=\frac{I_{\mathrm{a}}-I_{\mathrm{b}}}{I_{\mathrm{a}}+I_{\mathrm{b}}}$

where $I_{\mathrm{a}}$ and $I_{\mathrm{b}}$ are the intensities of the radiation passing the adjacent regions being imaged. As subject contrast and consequently image contrast are substantially affected by the quality of the incident X-ray spectra [26], we evaluated the influence of additional filters on both subject contrast (contrast in intensity domain) and image contrast (contrast in image domain) using the planar and cylindrical phantoms, respectively. In the planar phantom, the intensity contrast of all slabs was calculated according to Eq. (1), where $I_{\mathrm{b}}$ was set as the average of the intensities recorded by those detectors that are subtended by the ith slab's projection and $I_{\mathrm{a}}$ was set to the detectors subtended by the projection of the thinnest slab $(0.31 \mathrm{~mm})$. In the cylindrical phantom, the image contrast of all $\mathrm{K}_{2} \mathrm{HPO}_{4}$ solutions was also calculated according to Eq. (1) using a region-ofinterest (ROI)-based analysis, where $I_{\mathrm{b}}$ was the average of CT numbers in the ROI of the $i$ th solution and $I_{\mathrm{a}}$ the one with the lowest amount of $\mathrm{K}_{2} \mathrm{HPO}_{4}(0.12 \mathrm{~g} / \mathrm{cc})$, chosen as a reference material.

The formulation (1) is sometimes called modulation [36], as the intensity of the transmitted X-rays is modulated based on the subject's attenuating properties. This definition is in harmony with the definition of the modulation transfer function which describes how much contrast, or modulation, at a specific spatial frequency is maintained and transferred by the imaging system. Spatial resolution is another characteristic of image quality that is often quantitatively described by the MTF. It refers to the ability of distinguishing small, closely spaced objects. In this study, we also assessed the influence of $X$-ray filtration on image resolution using MTF measurements using the GE performance phantom. The MTF was experimentally measured using the standard deviation (SD) method [37], in which the transferred modulation of line-pair patterns, having different spatial frequencies, is determined from the standard deviation of CT numbers in ROls placed on the patterns. As shown in Fig. 2, three identical ROls were selected for each group of patterns; namely, $\mathrm{ROI}_{\mathrm{A}}$ for all line pairs of a given frequency, $\mathrm{ROI}_{\mathrm{B}}$ for Plexiglas region and $\mathrm{ROI}_{C}$ for water background. To obtain the contrast scale of the scanner required by the SD method, the difference of average $\mathrm{CT}$ numbers in $\mathrm{ROI}_{\mathrm{B}}$ and $\mathrm{ROI}_{C}$ was calculated. In the

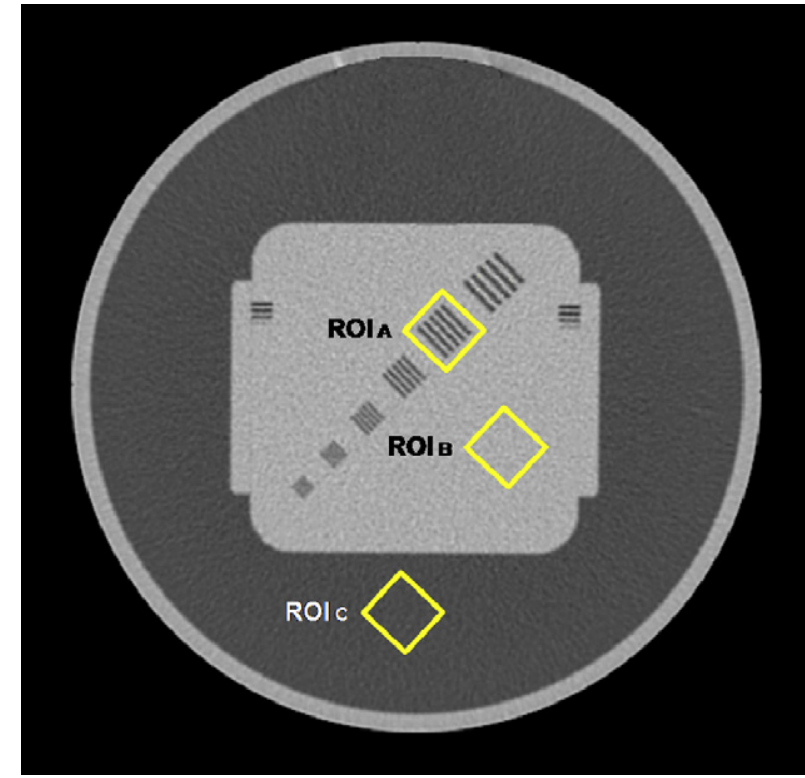

Figure 2 The GE performance phantom and the ROIs (A, B and $C$ ) selected for MTF calculations using the standard deviation method.

next step, the modulation at each spatial frequency was determined from the $\mathrm{SD}(\sigma)$ of the ROls according to Eq. (2), and then applied to Eq. (3). Thereby the MTF value at the corresponding frequency was obtained. In this study, we used the spatial frequency where the MTF falls to $50 \%$ of its maximum value, i.e. 50\% MTF value, to characterize the MTF performance of the scanner after adding additional filters.

Modulation $=\sqrt{\sigma_{\mathrm{A}}^{2}-\left(\frac{\sigma_{\mathrm{B}}+\sigma_{\mathrm{C}}}{2}\right)^{2}}$

MTF $=2.2 \times \frac{\text { Modulation }}{\text { Contrast scale }}$

As evident from the above approach, the noise represented by the standard deviation of CT numbers influences image resolution. It particularly limits the ability of differentiating low-contrast objects from their background, i.e. low-contrast detectability or contrast resolution [38]. Hence, the influence of X-ray filtration on image noise and the average of CT numbers were further studied using images of the cylindrical phantom for various thicknesses of additional filters.

\section{Patient dose evaluation}

The fundamental dose descriptor in CT is the CTDI which allows the estimation of patient dose from different scanning parameters setting. In this study, we used the weighted CTDI $\left(C T D I_{W}\right)$ which according to Eq. (4) provides a weighted sum of the central $\left(C T D I_{C}\right)$ and the peripheral $\left(C T D I_{P}\right)$ dose measurements in the CTDI phantom using a $100 \mathrm{~mm}$ ionization chamber.

$\mathrm{CTDI}_{\mathrm{W}}=\frac{1}{3} \times \mathrm{CTDI}_{\mathrm{C}}+\frac{2}{3} \times \mathrm{CTDI}_{\mathrm{P}}$ 
$\mathrm{CTDI}_{\mathrm{C}}$ and $\mathrm{CTDI}_{\mathrm{P}}$, were respectively, calculated from measurements in the centre and the average of the four measurements in the periphery of the phantom. In each measurement, the unused holes were plugged by the PMMA rods supplied with the phantom. The CTDI represents the average radiation dose across the diameter of the phantom and as such it represents a good measure of the average dose within the scanned volume.

\section{Figure of merit (FOM) formulation}

The assessment of image quality with regard to dose minimization is often carried out using a FOM $[27,30]$. To find the optimum thickness of the studied filters, we used a FOM defined as the ratio of the square of signal-to-noise ratio (SNR) and dose, SNR ${ }^{2} /$ Dose [26]. This FOM is also referred to as image-quality figure $[26,39]$ and dose-to-information conversion factor [40] in the literature. The above FOM can in fact be derived from the relationship between dose and resolution in CT imaging formulated as [6]:

$D=k \frac{\mathrm{SNR}^{2}}{R^{3} t}$

where $D$ is patient dose, SNR is signal-to-noise ratio, $R$ is the spatial resolution, $t$ is the slice thickness, and $k$ is a constant. The above equation implies that a twofold improvement in the SNR requires a fourfold increase in patient dose. In the definition of the FOM $\left(S_{N R}^{2} / D\right)$, the nominator $\mathrm{SNR}^{2}$ is divided by the dose. Using a ROI-based analysis of the CTDI phantom images, the SNR was calculated as the average of CT numbers of pixels within a ROI (10 $\mathrm{mm}$ diameter) divided by their standard deviation. Since the FOM is independent of the dose, an optimum filter is found at a thickness of the filter where the FOM reaches its maximum [26].

\section{Results}

Fig. 3a shows the counts recorded by the V-Res detector during the scanning of the planar phantom using an additional filter of $0.15 \mathrm{~mm} \mathrm{Cu}$ at $120 \mathrm{kVp}$. The overall bellshaped distribution of the counts is simply ascribed to the bow-tie beam shaping filter which gradually attenuates the intensity of X-ray fan-beams toward the edges of the beam. To evaluate the contrast in the intensity domain, the recorded counts should be corrected for the effect of the bow-tie filter. This correction was applied by dividing the counts recorded in a scan without the phantom in place (blank scan) to those recorded with the phantom in the field-of-view. The corrected count distribution is shown in Fig. 3b, in which different thicknesses of the $\mathrm{Cu}$ slabs account for the step-wise reduction of the counts, which was measured as a contrast factor according to Eq. (1). Fig. $4 \mathrm{a}$ and $\mathrm{b}$ shows the calculated contrast for the planar phantom as a function of the thickness of $\mathrm{Cu}$ and $\mathrm{Al}$ filters at $120 \mathrm{kVp}$. It can be seen that the contrast is somewhat compromised by filter thickness particularly in the case of additional $\mathrm{Cu}$ filters for slabs having higher thicknesses. Table 3 summarizes the percent change in the contrast of the slabs relative to the $0.13 \mathrm{~mm}$ reference slab for $\mathrm{Al}$ and $\mathrm{Cu}$ additional filters at 120 and $140 \mathrm{kVp}$.
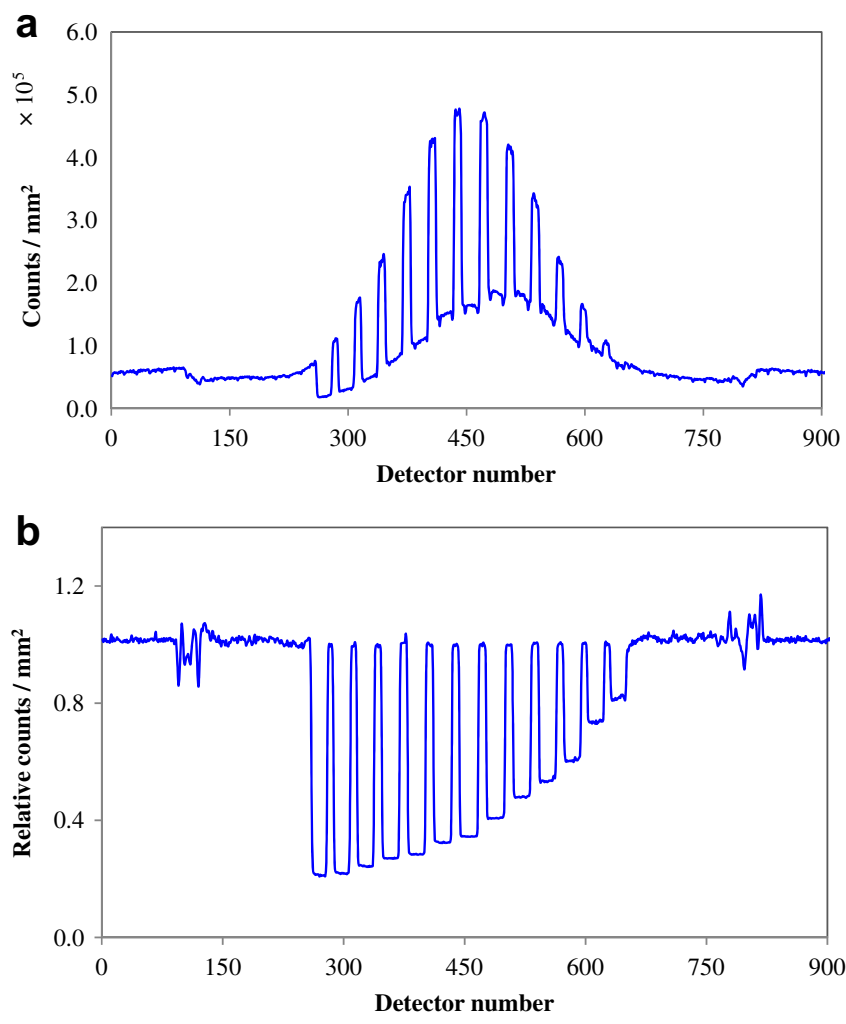

Figure 3 (a) The counts distribution recorded during the CT radiograph of the planar phantom with an additional filter of $0.15 \mathrm{~mm} \mathrm{Cu}$ at $120 \mathrm{kVp}$. (b) The counts corrected for the effect of the bow-tie filter using a blank scan.

Table 4 presents the relative reduction of $\mathrm{CT}$ numbers of $\mathrm{K}_{2} \mathrm{HPO}_{4}$ solutions in the cylindrical phantom relative to those obtained without adding beam hardening filter at tube voltages of 120 and $140 \mathrm{kVp}$. The results show that additional filters reduce the $\mathrm{CT}$ numbers. For instance, the $0.68 \mathrm{~mm} \mathrm{Cu}$ filter reduced the CT number of the $1.8 \mathrm{~g} / \mathrm{cc}$ $\mathrm{K}_{2} \mathrm{HPO}_{4}$ solution by about $12 \%$ while the $4.14 \mathrm{~mm}$ Al filter reduced it by about $3 \%$. Moreover, the $\mathrm{CT}$ number of solutions having higher amounts of $\mathrm{K}_{2} \mathrm{HPO}_{4}$ showed more reduction. This is illustrated in Fig. 5 in which representative slices of the polyethylene cylindrical phantom acquired with and without the $0.68 \mathrm{~mm}$ Cu filter at $140 \mathrm{kVp}$ together with the difference image are shown. As seen in Fig. $5 c$, the objects having higher amount of $\mathrm{K}_{2} \mathrm{HPO}_{4}$ (high density objects) show more difference in $\mathrm{CT}$ numbers compared to low-contrast objects.

Fig. 6 shows the image contrast calculated for the cylindrical phantom as a function of the thickness of $\mathrm{Cu}$ and Al filters at $120 \mathrm{kVp}$. The contrast is reduced with filter thickness markedly in low-contrast objects especially for $0.18 \mathrm{~g} / \mathrm{cc} \mathrm{K}_{2} \mathrm{HPO}_{4}$ sample for which added filters of $0.68 \mathrm{~mm}$ $\mathrm{Cu}$ and $4.14 \mathrm{~mm}$ Al reduced the contrast on average by $10.5 \%$ and $5.5 \%$, respectively. Table 5 presents the percent change in the contrast of the $\mathrm{K}_{2} \mathrm{HPO}_{4}$ solutions relative to the reference solution for $\mathrm{Cu}$ and $\mathrm{Al}$ additional filters at 120 and $140 \mathrm{kVps}$. Image noise in Hounsfield Unit (HU) for different $\mathrm{K}_{2} \mathrm{HPO}_{4}$ solutions of the cylindrical phantom is shown in Fig. 7 for different thicknesses of $\mathrm{Cu}$ and Al filters at $140 \mathrm{kVp}$. As expected added filtration, especially with $\mathrm{Cu}$ 


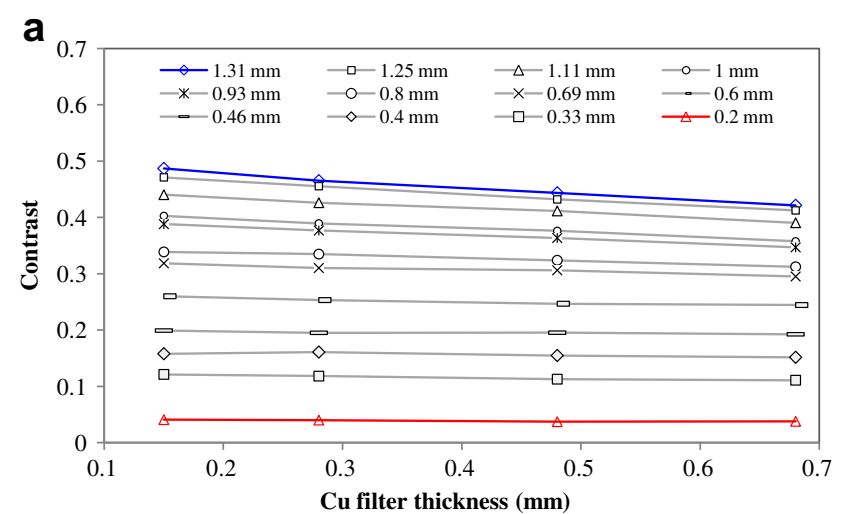

b

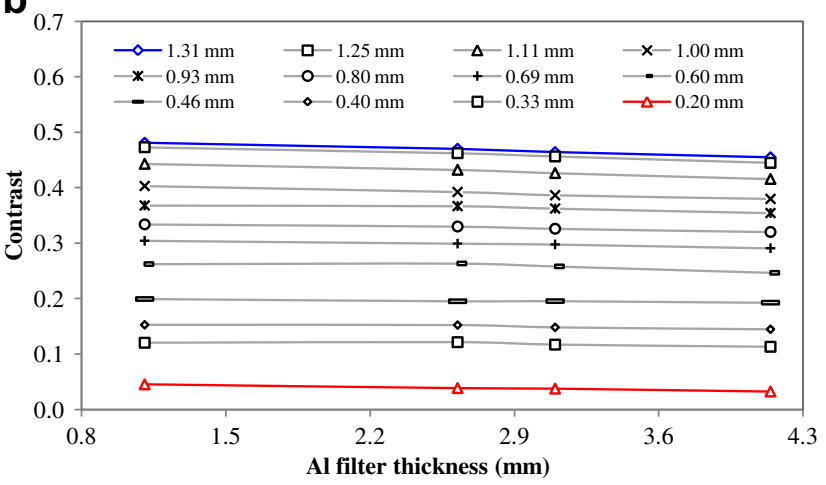

Figure 4 The intensity contrast calculated for the planar phantom as a function of filter thickness for (a) $\mathrm{Cu}$ and (b) $\mathrm{Al}$ filters at $120 \mathrm{kVp}$.

filter, increases image noise thereby the detectability of low-contrast (low-density) objects is impaired. The noise evaluation showed that for high concentrations of $\mathrm{K}_{2} \mathrm{HPO}_{4}$, there is substantial increase of noise, that is, the CT numbers are subject to more variations.
The MTF performance of the scanner for different additional $\mathrm{Cu}$ filters indicates that by increasing the filter thickness, the MTF and hence the spatial resolution is compromised (Fig. 8). Table 6 presents the 50\% MTF value for the Cu filter at 120 and $140 \mathrm{kVps}$. The results show that when using the $0.68 \mathrm{~mm}$ Cu filter, the spatial frequency of $50 \%$ MTF shifts from 4.81 to $4 \mathrm{lp} / \mathrm{mm}$ at $120 \mathrm{kVp}$ and from 5.11 to $4.58 \mathrm{lp} / \mathrm{mm}$ at $140 \mathrm{kVp}$. The results of $\mathrm{CTDI}_{\mathrm{W}}$ measurements as a function of Cu filter thickness are shown in Fig. 9. As can be seen, the $\mathrm{CTDI}_{\mathrm{W}}$ decreases substantially with filter thickness in such a way that it gets reduced to $50 \%$ by about 0.41 and $0.55 \mathrm{~mm} \mathrm{Cu}$ filter for tube potentials of 120 and $140 \mathrm{kVp}$, respectively. Therefore pre-filtering plays a pivotal role to substantially reduce patient dose in CT imaging. However, it necessitates an optimum filter by which the reconstructed images still retain their diagnostic quality.

Fig. 10 shows the FOM estimates for the determination of the optimal filter as a function of $\mathrm{Cu}$ and $\mathrm{Al}$ filter thickness at 120 and $140 \mathrm{kVp}$ tube potentials. The curves are normalized to zero filtration and represent the variation of dose per unit detected photon for increasing $\mathrm{Cu}$ filtration. When selecting a filter thickness corresponding to the maximum values of these curves, a good compromise between image quality and radiation exposure of the patient is achieved. As Fig. 10a indicates, an optimum $\mathrm{Cu}$ filter thickness for 120 and $140 \mathrm{kVp}$ is around $0.5 \mathrm{~mm}$ at which the FOM reaches a plateau whereas an optimum $\mathrm{Al}$ filter thickness for 120 and $140 \mathrm{kVp}$ is more than $4 \mathrm{~mm}$ (Fig. 10b). It should be noted that the FOM should in principle achieve a maximum corresponding to an optimum filter, however, in practice when the FOM curves begin to reach a plateau can indicate such an optimum filter [27].

\section{Discussion}

In X-ray CT and projection radiography, beam filtration is an efficient means to reduce low-energy X-rays having no or

Table 3 Relative change of the contrast of the planar phantom for different thicknesses of Al and Cu additional filters at tube potentials of 120 and $140 \mathrm{kVp}$.

\begin{tabular}{|c|c|c|c|c|c|c|c|c|c|c|}
\hline \multirow{2}{*}{$\begin{array}{l}\text { Tube potential } \\
(\mathrm{kVp})\end{array}$} & \multirow{2}{*}{$\begin{array}{l}\text { Added filtration } \\
(\mathrm{mm})\end{array}$} & \multicolumn{9}{|c|}{ Slab thickness (mm) } \\
\hline & & 0.20 & 0.33 & 0.40 & 0.60 & 0.80 & 0.93 & 1.00 & 1.25 & 1.31 \\
\hline \multirow[t]{8}{*}{120} & $1.06 \mathrm{Al}$ & 0.2 & 0.1 & -0.1 & -0.2 & -0.4 & -0.3 & -0.4 & -0.2 & -0.3 \\
\hline & $2.60 \mathrm{Al}$ & -0.1 & -1.3 & -1.5 & -1.8 & -1.8 & -1.9 & -2.0 & -1.8 & -2.4 \\
\hline & $3.08 \mathrm{Al}$ & -0.3 & -1.8 & -1.7 & -2.0 & -1.6 & -2.2 & -2.3 & -2.2 & -2.3 \\
\hline & $4.14 \mathrm{Al}$ & -0.8 & -2.0 & -2.3 & -2.8 & -0.7 & -2.8 & -3.1 & -3.2 & -3.2 \\
\hline & $0.15 \mathrm{Cu}$ & 0.0 & -2.6 & -1.4 & -2.8 & -3.1 & -3.4 & -3.5 & -3.3 & -4.0 \\
\hline & $0.28 \mathrm{Cu}$ & -1.9 & -5.1 & 0.5 & -5.3 & -4.2 & -6.2 & -6.7 & -6.5 & -7.3 \\
\hline & $0.48 \mathrm{Cu}$ & -7.3 & -7.4 & -3.4 & -7.7 & -7.4 & -9.5 & -9.8 & -10.0 & -10.5 \\
\hline & $0.68 \mathrm{Cu}$ & -9.0 & -9.7 & -6.4 & -8.6 & -10.7 & -13.6 & -14.3 & -14.9 & -15.6 \\
\hline \multirow[t]{8}{*}{140} & $1.06 \mathrm{Al}$ & 0.1 & -0.2 & 0.3 & -0.1 & -0.3 & -0.2 & -0.4 & -0.3 & -0.4 \\
\hline & $2.60 \mathrm{Al}$ & -1.2 & -1.3 & -1.6 & -1.5 & -1.7 & -1.8 & -1.7 & -1.8 & -2.2 \\
\hline & $3.08 \mathrm{Al}$ & -1.7 & -2.0 & -1.7 & -1.8 & -2.1 & -2.3 & -1.4 & -2.4 & -2.7 \\
\hline & $4.14 \mathrm{Al}$ & -2.6 & -3.5 & -3.4 & -2.9 & -3.1 & -3.5 & -2.6 & -3.6 & -4.2 \\
\hline & $0.15 \mathrm{Cu}$ & -1.8 & -2.5 & -2.3 & -2.5 & -3.2 & -3.5 & -3.6 & -3.8 & -4.2 \\
\hline & $0.28 \mathrm{Cu}$ & -4.3 & -5.7 & -5.8 & -5.2 & -6.3 & -7.2 & -6.6 & -7.8 & -8.6 \\
\hline & $0.48 \mathrm{Cu}$ & -8.2 & -9.6 & -8.7 & -8.8 & -9.8 & -10.7 & -9.2 & -10.9 & -11.7 \\
\hline & $0.68 \mathrm{Cu}$ & -9.5 & -10.9 & -10.7 & -12.0 & -14.0 & -15.3 & -13.8 & -16.4 & -17.5 \\
\hline
\end{tabular}


Table 4 Relative change of $\mathrm{CT}$ numbers of the $\mathrm{K}_{2} \mathrm{HPO}_{4}$ solutions in the cylindrical phantom for different thicknesses of $\mathrm{Al}$ and $\mathrm{Cu}$ additional filters at 120 and $140 \mathrm{kVp}$.

\begin{tabular}{|c|c|c|c|c|c|c|c|c|c|c|}
\hline \multirow{2}{*}{$\begin{array}{l}\text { Tube potential } \\
(\mathrm{kVp})\end{array}$} & \multirow{2}{*}{$\begin{array}{l}\text { Added filtration } \\
(\mathrm{mm})\end{array}$} & \multicolumn{9}{|c|}{$\mathrm{K}_{2} \mathrm{HPO}_{4}$ solution $(\mathrm{gr} / \mathrm{cc})$} \\
\hline & & 0.18 & 0.24 & 0.30 & 0.48 & 0.60 & 0.90 & 1.20 & 1.50 & 1.80 \\
\hline \multirow[t]{8}{*}{120} & $1.06 \mathrm{Al}$ & -0.4 & -0.8 & -0.6 & -0.7 & -0.6 & -0.7 & -0.7 & -0.6 & -0.7 \\
\hline & $2.60 \mathrm{Al}$ & -0.2 & -0.6 & -0.6 & -1.0 & -1.1 & -1.2 & -1.2 & -1.2 & -1.4 \\
\hline & $3.08 \mathrm{Al}$ & -0.4 & -0.5 & -0.9 & -1.5 & -1.6 & -1.7 & -2.0 & -1.8 & -2.1 \\
\hline & $4.14 \mathrm{Al}$ & -0.3 & -0.3 & -0.7 & -1.7 & -1.8 & -2.3 & -2.4 & -2.5 & -2.7 \\
\hline & $0.15 \mathrm{Cu}$ & -3.2 & -3.7 & -3.6 & -3.7 & -3.5 & -3.6 & -3.6 & -3.6 & -3.7 \\
\hline & $0.28 \mathrm{Cu}$ & -5.4 & -5.9 & -6.1 & -6.4 & -6.2 & -6.7 & -6.7 & -6.6 & -6.8 \\
\hline & $0.48 \mathrm{Cu}$ & -5.7 & -7.1 & -7.6 & -8.6 & -8.6 & -9.3 & -9.5 & -9.5 & -9.8 \\
\hline & $0.68 \mathrm{Cu}$ & -5.9 & -8.1 & -8.9 & -10.3 & -10.4 & -11.3 & -11.5 & -11.7 & -12.1 \\
\hline \multirow[t]{8}{*}{140} & $1.06 \mathrm{Al}$ & -0.8 & -0.9 & -0.9 & -0.9 & -0.7 & -0.8 & -0.7 & -0.9 & -0.9 \\
\hline & $2.60 \mathrm{Al}$ & -0.3 & -0.6 & -1.2 & -1.4 & -1.5 & -1.9 & -1.9 & -2.2 & -2.0 \\
\hline & $3.08 \mathrm{Al}$ & -0.3 & -0.2 & -0.8 & -1.5 & -1.6 & -1.9 & -2.1 & -2.2 & -2.3 \\
\hline & $4.14 \mathrm{Al}$ & -0.6 & -0.1 & -0.7 & -1.6 & -1.8 & -2.3 & -2.5 & -2.6 & -2.8 \\
\hline & $0.15 \mathrm{Cu}$ & -3.7 & -3.8 & -3.9 & -3.8 & -3.6 & -3.8 & -3.8 & -3.9 & -3.9 \\
\hline & $0.28 \mathrm{Cu}$ & -5.7 & -6.0 & -6.1 & -6.4 & -6.2 & -6.6 & -6.6 & -6.8 & -6.8 \\
\hline & $0.48 \mathrm{Cu}$ & -6.8 & -7.8 & -8.3 & -9.0 & -8.9 & -9.7 & -9.8 & -9.9 & -10.2 \\
\hline & $0.68 \mathrm{Cu}$ & -7.4 & -8.8 & -9.5 & -10.9 & -10.9 & -12.0 & -12.1 & -12.4 & -12.7 \\
\hline
\end{tabular}

little contribution to image formation, whereby both patient dose and beam hardening artefacts are reduced. This study was conducted to determine experimentally an optimum copper and aluminium filter thickness for beam filtration in the GE VCT 64-slice CT scanner in order to decrease patient's dose without considerably sacrificing image quality.

Most CT scanners are equipped with a beam shaper or bow-tie filter that minimizes radiation exposure in the thinner portions of patient's anatomy, thus providing better noise consistency within the image plane while saving up to $50 \%$ surface radiation dose [41]. In the present study, we investigate an optimum flat filter in the presence of the scanner's bow-tie filter. As demonstrated in Fig. 4, the contrast of the planar phantom, corrected for the bow-tie filter and calculated according to Eq. (1), decreases with filter thickness particularly in thinner slabs representing thin tissue layers. This further confirms that additional beam hardening filters especially those made of copper degrade object contrast in low absorbing materials. According to Table 3, at a given filter thickness, the contrast of the slabs decreases with tube potential in particular in thicker ones. In other words, the difference between the counts transmitted through the reference slab and thick slabs decrease with tube potential. Since prefiltering makes X-ray spectra harder, the attenuation Xrays experience decreases because most of interactions would be primarily Compton scattering rather than photoelectric absorption. Consequently, as demonstrated in Table 4, the obtained CT numbers portrayed as image grayscale values are reduced. The $\mathrm{CT}$ numbers of different $\mathrm{K}_{2} \mathrm{HPO}_{4}$ solutions in the cylindrical phantom were reduced, on average, by $10.1 \%$ for a $0.68 \mathrm{~mm}$ copper filter and by $1.7 \%$ for a $4.14 \mathrm{~mm}$ aluminium filter at tube potentials of 120 and $140 \mathrm{kVp}$, respectively. The results indicate that by making use of the mentioned additional filter, CT numbers decrease by up to $10 \%$ which may be of little consequences in the light of image processing and display techniques. The results presented in Table 5 give an indication of the degree by which the detectability of low contrast objects is compromised by additional beam hardening filters. The results show that the contrast of the solutions having low amount of $\mathrm{K}_{2} \mathrm{HPO}_{4}$ is more affected and degraded by up to about $10 \%$ and $6 \%$ using a filter of $0.68 \mathrm{~mm} \mathrm{Cu}$ and $4.14 \mathrm{~mm}$
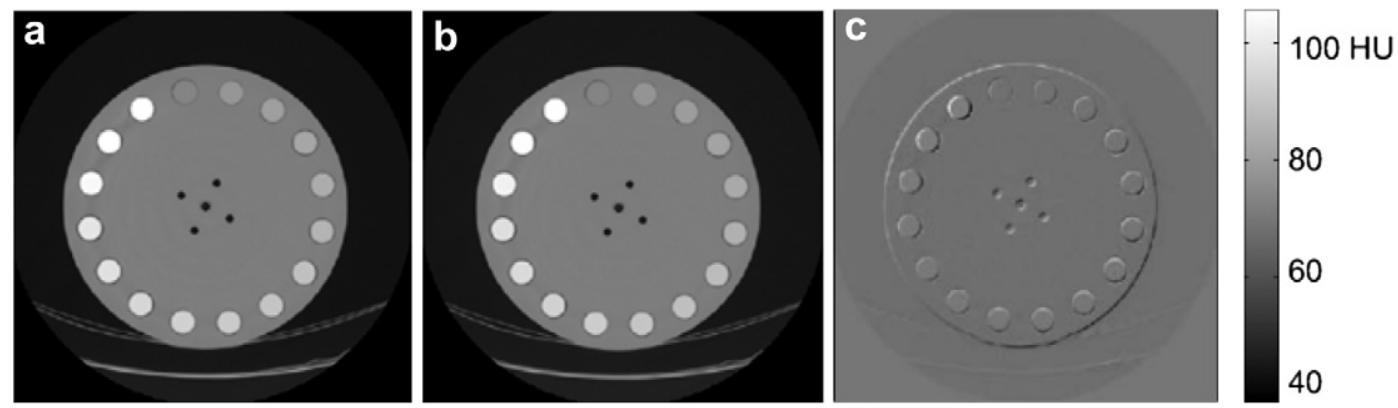

Figure 5 Representative slices of the cylindrical phantom acquired at $140 \mathrm{kVp}$. (a) CT image acquired without additional filter and (b) with an additional $0.68 \mathrm{~mm}$ Cu filter. (c) The difference image between (a) and (b). 


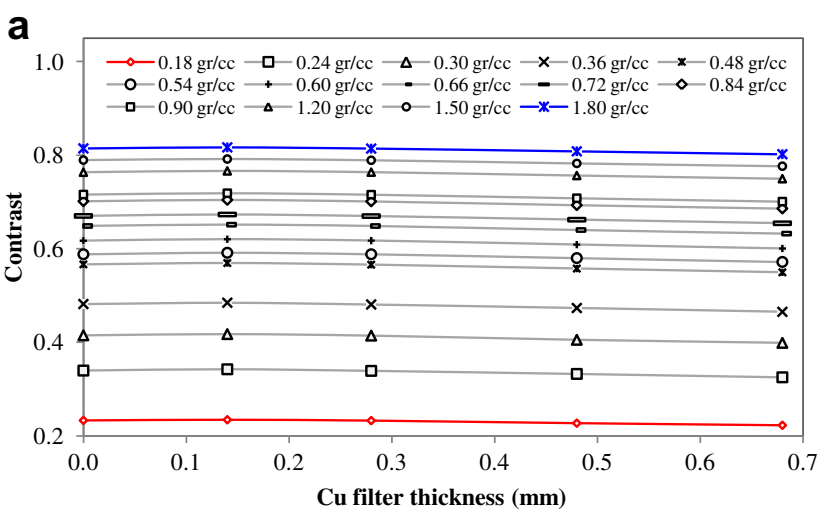

b

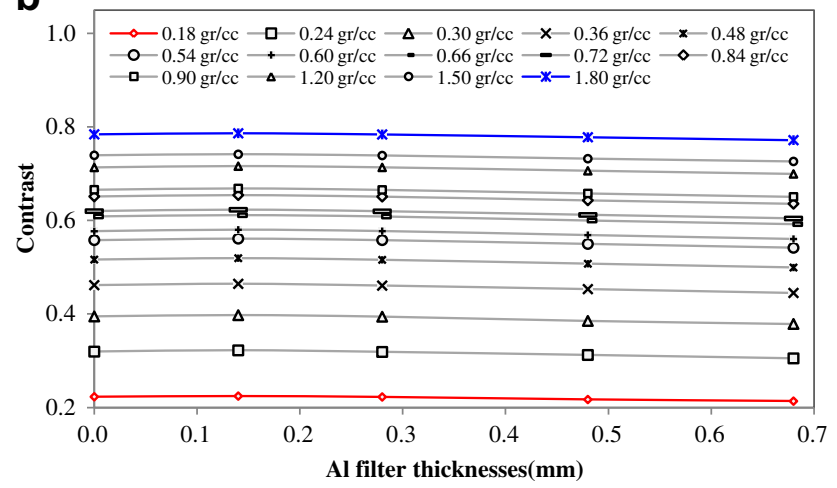

Figure 6 Image contrast calculated for the cylindrical phantom as a function of filter thickness for (a) $\mathrm{Cu}$ and (b) $\mathrm{Al}$ filters at $12 \mathrm{kVp}$.

$\mathrm{Al}$, respectively. However, as observed in projection radiology with an additional filter of $4 \mathrm{~mm}$ Al [42], image contrast is not considerably impaired. With increasing tube potential, quantum noise limiting low-contrast detectability decreases, thereby as demonstrated in Table 5 the degree to which the contrast is compromised is reduced. Generally, the variance of the estimated attenuation in a volume element is proportional to the reciprocal of the number of photons detected passing through that volume [43]. According to Fig. 7, the noise is more pronounced for high-density samples, which should be ascribed to their higher electron density accounting for more X-ray attenuation within the samples. However, according to the results in Table 5, the image contrast of these high-density samples is less degraded by noise compared to low-density samples.

The resolution measure given by the 50\% MTF value presented in Table 6 indicates that pre-filtering degrades image resolution because it gives rise to increased image noise dominated by quantum mottle overlaying the image information. The results show that a $0.48 \mathrm{~mm} \mathrm{Cu}$ filter shifts the $50 \%$ MTF value by approximately $0.77 \mathrm{lp} / \mathrm{cm}$ compared to when the filter is not used. This indicates that one can face a good trade-off between image quality and patient dose with this filter thickness. By increasing tube potential, the $50 \%$ MTF values denote improvement in image resolution due to decreasing quantum mottle with the increased number of $\mathrm{X}$-rays brought about by tube potential (Table 6). The CTDI ${ }_{W}$ measurements showed that a Cu filter of approximately $0.5 \mathrm{~mm}$ thickness accounts for $50 \%$ reduction in radiation absorbed dose while such a filter reduces the image contrast of the cylindrical phantom by about $4 \%$ (Table 5) averaged over tube potentials of 120 and $140 \mathrm{kVp}$. It is worth noting that in the presence of bow-tie filters, the additional flat filters particularly affect the dose in the central portions of the CTDI phantom $\left(C T D I_{C}\right)$ because as mentioned above, the bow-tie filters preferentially reduce the dose toward the peripheral portions, thereby making the beams harder and more penetrating in the edges of the beams. The FOM results shown in Fig. 10 indicate that an additional filter of $0.5 \mathrm{~mm} \mathrm{Cu}$ should be optimum at high $\mathrm{kVp} C \mathrm{CT}$ acquisitions in the LightSpeed VCT scanner, while consistent with the results of Sculz and Judy

Table 5 Relative change of the contrast of $\mathrm{K}_{2} \mathrm{HPO}_{4}$ solutions in the cylindrical phantom for different thicknesses of Al and $\mathrm{Cu}$ additional filters at 120 and $140 \mathrm{kVps}$.

\begin{tabular}{|c|c|c|c|c|c|c|c|c|c|c|}
\hline \multirow{2}{*}{$\begin{array}{l}\text { Tube potential } \\
(k V p)\end{array}$} & \multirow{2}{*}{$\begin{array}{l}\text { Added filtration } \\
(\mathrm{mm})\end{array}$} & \multicolumn{9}{|c|}{$\mathrm{K}_{2} \mathrm{HPO}_{4}$ solution $(\mathrm{gr} / \mathrm{cc})$} \\
\hline & & 0.18 & 0.24 & 0.30 & 0.48 & 0.60 & 0.90 & 1.20 & 1.50 & 1.80 \\
\hline \multirow[t]{8}{*}{120} & $1.06 \mathrm{Al}$ & 0.5 & 0.9 & 0.2 & 0.7 & 0.7 & 0.6 & 0.5 & 0.5 & 0.4 \\
\hline & $2.60 \mathrm{Al}$ & 0.7 & -0.2 & 0.1 & -0.1 & 0.0 & 0.0 & 0.0 & 0.0 & 0.0 \\
\hline & $3.08 \mathrm{Al}$ & -2.4 & -2.8 & -2.1 & -1.5 & -1.4 & -1.0 & -0.8 & -0.7 & -0.7 \\
\hline & $4.14 \mathrm{Al}$ & -5.6 & -5.1 & -4.3 & -3.3 & -2.8 & -2.2 & -1.8 & -1.6 & -1.5 \\
\hline & $0.15 \mathrm{Cu}$ & -0.8 & -1.3 & -0.9 & -0.6 & -0.4 & -0.3 & -0.3 & -0.2 & -0.2 \\
\hline & $0.28 \mathrm{Cu}$ & -3.2 & -2.8 & -2.3 & -1.6 & -1.2 & -1.1 & -0.9 & -0.8 & -0.7 \\
\hline & $0.48 \mathrm{Cu}$ & -7.1 & -6.6 & -5.6 & -4.2 & -3.5 & -2.8 & -2.3 & -2.2 & -2.0 \\
\hline & $0.68 \mathrm{Cu}$ & -10.9 & -10.3 & -8.8 & -6.5 & -5.5 & -4.3 & -3.7 & -3.3 & -3.1 \\
\hline \multirow[t]{8}{*}{140} & $1.06 \mathrm{Al}$ & 0.8 & 0.9 & 0.7 & 0.6 & 0.6 & 0.4 & 0.4 & 0.3 & 0.3 \\
\hline & $2.60 \mathrm{Al}$ & -0.2 & -0.2 & -0.2 & -0.1 & 0.0 & -0.1 & 0.0 & -0.1 & 0.0 \\
\hline & $3.08 \mathrm{Al}$ & -3.3 & -2.6 & -2.7 & -1.8 & -1.5 & -1.2 & -1.0 & -1.0 & -0.8 \\
\hline & $4.14 \mathrm{Al}$ & -6.0 & -5.2 & -4.6 & -3.4 & -3.0 & -2.3 & -2.0 & -1.8 & -1.7 \\
\hline & $0.15 \mathrm{Cu}$ & -0.5 & -0.4 & -0.5 & -0.2 & -0.1 & -0.1 & -0.1 & -0.1 & -0.1 \\
\hline & $0.28 \mathrm{Cu}$ & -3.2 & -2.5 & -2.1 & -1.4 & -1.1 & -1.0 & -0.8 & -0.7 & -0.7 \\
\hline & $0.48 \mathrm{Cu}$ & -6.4 & -5.5 & -4.8 & -3.5 & -2.8 & -2.4 & -2.0 & -1.8 & -1.7 \\
\hline & $0.68 \mathrm{Cu}$ & -10.2 & -8.6 & -7.4 & -5.7 & -4.7 & -3.8 & -3.2 & -3.0 & -2.8 \\
\hline
\end{tabular}



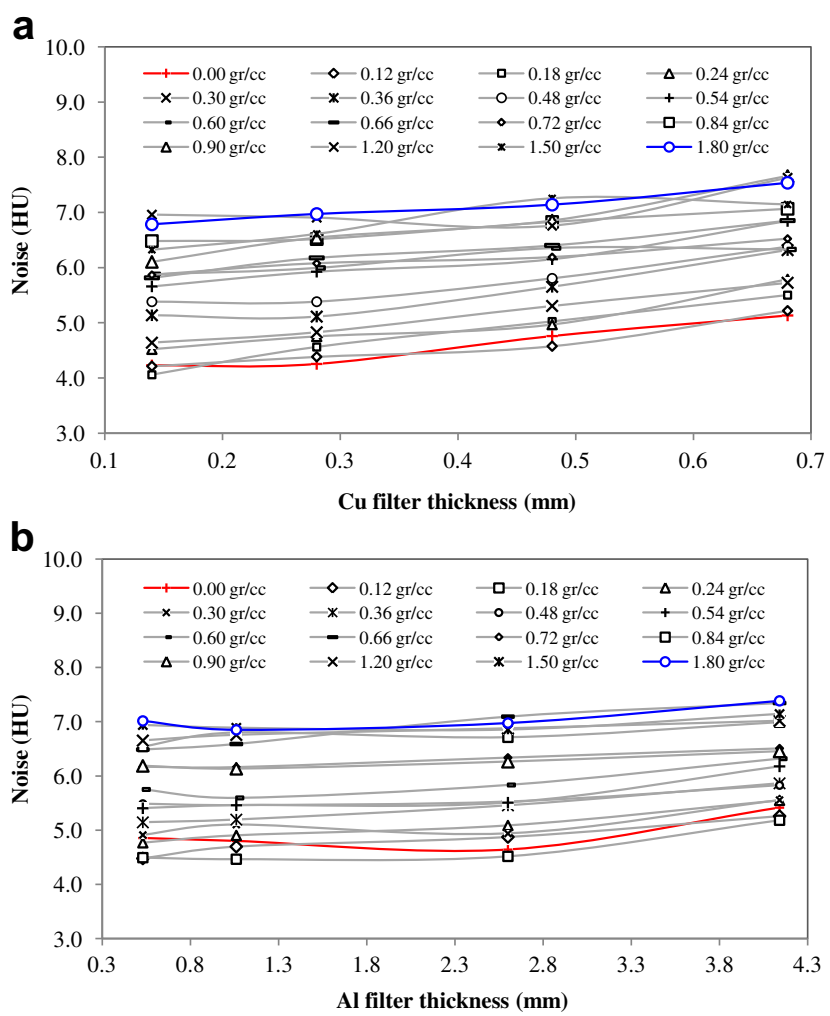

Figure 7 Image noise calculated for different $\mathrm{K}_{2} \mathrm{HPO}_{4}$ solutions of the cylindrical phantom as a function of filter thickness for (a) $\mathrm{Cu}$ and (b) Al filters at $140 \mathrm{kVp}$ and $200 \mathrm{~mA}$.

[27], an aluminium filter of more than $4 \mathrm{~mm}$ thickness would be an optimal filter thickness. The absorption of lowenergy X-rays and resulting reduction of absorbed dose by the added filters account for the initial rapid increase of the FOM which demonstrates patient dose reduction without significant loss in image quality. The results show that the recommended additional filtrations should be prudent and advantageous, because higher thicknesses might greatly reduce the number of photons available for the purpose of imaging and therefore have implications in tube loading due to increasing exposure conditions. At the end, it is worth to highlight the limitations accepted and assumptions made in this study. Although, the phantom or

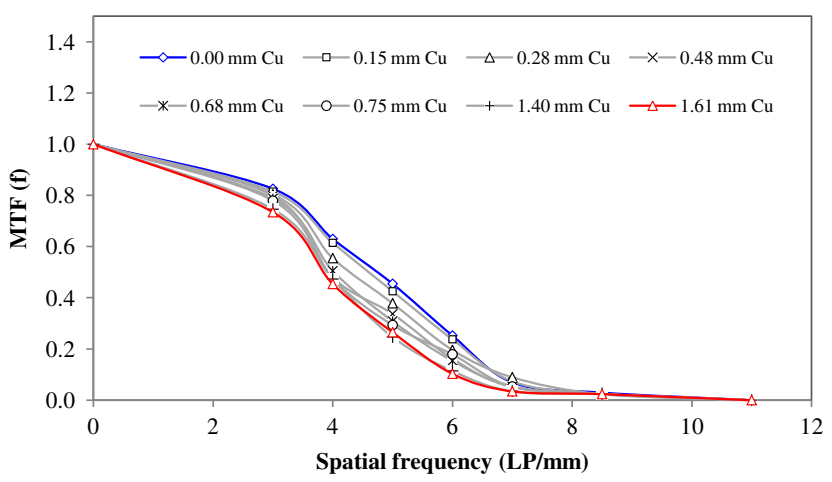

Figure 8 MTF curves calculated for different $\mathrm{Cu}$ filter thicknesses at tube potential of $120 \mathrm{kVp}$.
Table 6 The 50\% MTF values calculated from the GE performance phantom for different thicknesses of $\mathrm{Cu}$ additional filters at 120 and $140 \mathrm{kVps}$.

\begin{tabular}{lll}
\hline Added filtration $(\mathrm{mm})$ & \multicolumn{2}{c}{ Tube potential $(\mathrm{kVp})$} \\
\cline { 2 - 3 } & 120 & 140 \\
\hline $0.00 \mathrm{Cu}$ & 4.81 & 5.11 \\
$0.15 \mathrm{Cu}$ & 4.62 & 5.02 \\
$0.28 \mathrm{Cu}$ & 4.30 & 4.98 \\
$0.48 \mathrm{Cu}$ & 4.04 & 4.78 \\
$0.68 \mathrm{Cu}$ & 4.00 & 4.58 \\
$0.75 \mathrm{Cu}$ & 3.98 & 4.42 \\
$1.40 \mathrm{Cu}$ & 3.96 & 4.38 \\
$1.61 \mathrm{Cu}$ & 3.80 & 4.15 \\
\hline
\end{tabular}

patient size and the bow-tie filter shape adapted influence on patient dose and image quality [44], we conducted the dose measurements using a standard CTDI head phantom. However, this might be viewed as a limitation in the filter optimization task. Furthermore, as the radiation beam widths in multi-slice scanners are fairly wide, the broad scatter tails of the single slice profile may not sufficiently collected with a $100 \mathrm{~mm}$ long ion chamber scanner [45]. Therefore, the CTDI measurements might have been underestimated. Finally, instead of a wide range of kilovoltage peaks, we considered high $k V p C T$ acquisitions and just focused on filter optimizations.

Pre-filtering using additional flat filters has been established as one of the fundamental methods in beam hardening correction and patient dose reduction. The propagation of polychromatic X-ray beams and beam hardening effects have been appropriately addressed by the recently proposed statistical image reconstruction algorithms that far surpass their conventional filtered backprojection counterpart $[46,47]$. Furthermore, the introduction of new CT technologies such as fast kVp switching have allowed dual-energy CT imaging to be reintroduced in this context. However, additional beam hardening filters remain an integral part of the procedures aiming at providing high quality diagnostic images with minimum patient dose.

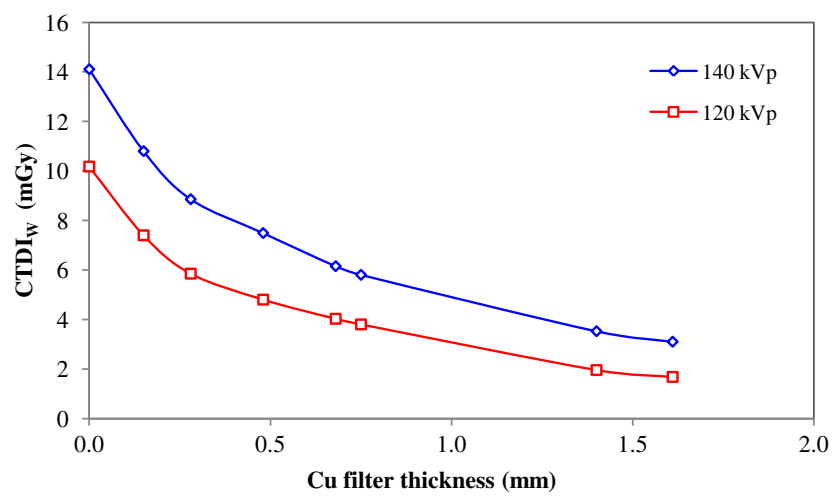

Figure 9 Weighted CTDI calculated for different $\mathrm{Cu}$ filter thicknesses using the head CTDI phantom at tube potentials of 120 and $140 \mathrm{kVp}$. 


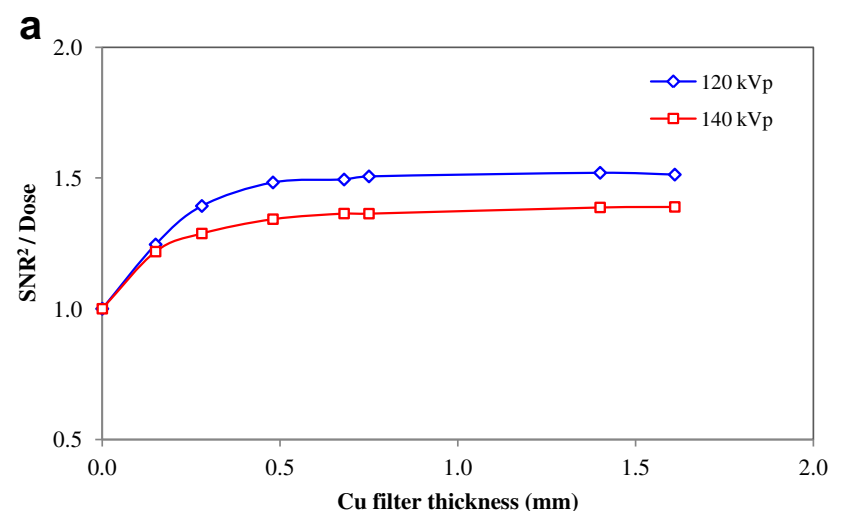

b

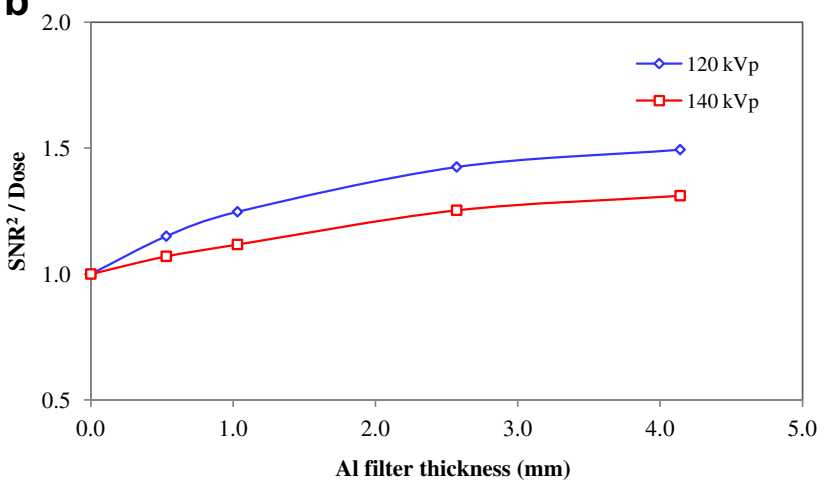

Figure 10 Figure of merit (FOM) estimates as a function of (a) Cu filter and (b) Al filter thicknesses at tube potentials of 120 and $140 \mathrm{kVp}$.

\section{Conclusion}

This experimental study was intended to determine an optimum copper and aluminium additional flat filters in the GE VCT 64-slice CT scanner using standard and specially designed phantoms. According to the FOM considering dose and noise, our results demonstrate that with an additional filter of $0.5 \mathrm{~mm}$ copper or minimum $4 \mathrm{~mm}$ aluminium, patient dose is considerably reduced at tube potentials of 120 and $140 \mathrm{kVp}$, whereas image quality described by contrast and spatial resolution is slightly, nonetheless, prudently compromised. However, further assessment of the scanner's dose efficiency and image quality should be performed with the recommended filters in a clinical setting.

\section{Conflict of interest statement}

The authors declare that they have no conflict of interest.

\section{Acknowledgments}

This work was supported by the Research Center for Science and Technology in Medicine and Tehran University of Medical Sciences, Tehran, Iran under grant No. 7719, the Swiss National Science Foundation under grant SNSF 31003A-135576, Geneva University Hospital under grant PRD 11-II-1, Geneva Cancer League and the Indo-Swiss Joint Research Programme ISJRP 138866.

\section{References}

[1] Rogalla P, Kloeters C, Hein PA. CT technology overview: 64slice and beyond. Radiol Clin North Am 2009;47:1-11.

[2] Nieman K, Cademartiri F, Lemos PA, Raaijmakers R, Pattynama PM, de Feyter PJ. Reliable noninvasive coronary angiography with fast submillimeter multislice spiral computed tomography. Circulation 2002;106:2051-4.

[3] Nickoloff EL, Alderson PO. Radiation exposures to patients from CT: reality, public perception, and policy. AJR Am J Roentgenol 2001;177:285-7.

[4] ICRP. Managing patient dose in multi-detector computed tomography (MDCT). ICRP publication 102. Ann ICRP 2007;37: $1-79$.

[5] Maiello ML. Ionizing radiation exposure of the population of the United States. Health Phys; 2010:549-50. National Council on Radiation Protection and Measurements.

[6] Hendee WR, Ritenour ER. Medical imaging physics. 4th ed. Wiley-Liss, Inc; 2002.

[7] Kak AC, Slaney M. Principles of computerized tomographic imaging. Piscataway, NJ: IEEE Press; 1988.

[8] Duerinckx AJ, Macovski A. Polychromatic streak artifacts in computed tomography images. J Comput Assist Tomogr 1978; 2:481-7.

[9] Herman GT. Demonstration of beam hardening correction in computed tomography of the head. J Comput Assist Tomogr 1979;3:373-8.

[10] Rao PS, Alfidi RJ. The environmental density artifact: a beamhardening effect in computed tomography. Radiology 1981; 141:223-7.

[11] Moström U, Ytterbergh C. Artifacts in computed tomography of the posterior fossa: a comparative phantom study. J Comput Assist Tomogr 1986;10:560-6.

[12] Maki DD, Birnbaum BA, Chakraborty DP, Jacobs JE, Carvalho BM, Herman GT. Renal cyst pseudoenhancement: beam-hardening effects on CT numbers. Radiology 1999;213:468-72.

[13] Di Chiro G, Brooks RA, Dubal L, Chew E. The apical artifact: elevated attenuation values toward the apex of the skull. J Comput Assist Tomogr 1978;2:65-70.

[14] Brooks RA, Chiro GD. Beam hardening in X-ray reconstruction tomography. Phys Med Biol 1976;21:390-8.

[15] MCDavid WD, Waggener RG, Payne WH, Denis MJ. Correction for spectral artifacts in cross-sectional reconstruction from Xrays. Med Phys 1997;4:54-7.

[16] Herman GT. Correction for beam hardening in computed tomography. Phys Med Biol 1979;24:81-106.

[17] Pang SC, Genna S. Correction for X-ray polychromaticity effects on three-dimensional reconstruction. IEEE Trans Nucl Sci 1976;23:623-6.

[18] Joseph PM, Spital RD. A method for correcting bone induced artifacts in computed tomography scanners. J Comput Assist Tomogr 1978;2:100-8.

[19] Kijewski PK, Bjärngard BE. Correction for beam hardening in computed tomography. Med Phys 1978;5:209-14.

[20] Nalcioglu O, Lou RY. Post-reconstruction method for beam hardening in computerized tomography. Phys Med Biol 1979; 24:330-40.

[21] Meagher JM, Mote CD, Skinner HB. CT image correction for beam hardening using simulated projection data. IEEE Trans Nucl Sci 1990;37:1520-4.

[22] Chen C-Y, Chuang K-S, Wu J, Lin H-R, Li M-J. Beam hardening correction for computed tomography images using a postreconstruction method and equivalent tissue concept. J Digital Imag 2001;14:54-61.

[23] Coleman AJ, Sinclair M. A beam-hardening correction using dual-energy computed tomography. Phys Med Biol 1985;30: 1251. 
[24] Hemmingsson A, Jung B, Ytterbergh C. Dual energy computed tomography: simulated monoenergetic and material-selective imaging. J Comput Assist Tomogr 1986;10:490-9.

[25] Alvarez RE, Macovski A. Energy-selective reconstruction in Xray computerized tomography. Phys Med Biol 1976;21:733-44.

[26] Aichinger H, Dierker J, Joite-BarfuB S, Sabel M. Radiation exposure and image quality in X-ray diagnostic radiology, Physical principles and clinical applications. 1st ed. Berlin Heidelberg: Springer; 2004.

[27] Szulc M, Judy PF. Effect of X-ray source filtration on dose and image performance of CT scanners. Med Phys 1979;6:479-86.

[28] Jennings RJ. A method for comparing for beam-hardening filter materials for diagnostic radiology. Med Phys 1998;15: 588-99.

[29] Siedband MP. Beam filtration in diagnostic radiology. ASTM STP 716. In: Garrett DA, Brachem DA, editors. Real-time radiologie imaging: medical and industrial applications. American Society for Testing and Materials; 1987.

[30] Kohn ML, Gooch AW, Keller WS. Filters for radiation reduction: a comparison. Radiology 1988;167:255-7.

[31] Morrell RE, Rogers AT, Jobling JC, Shakespeare KE. Barium enema: use of increased copper filtration to optimize dose and image quality. Br J Radiol 2004;77:116-22.

[32] Nagel HD. CT parameters that influence the radiation dose. In: Tack D, Gevenois PA, editors. Radiation dose from adult and pediatric multidetector computed tomography. Verlag Berlin Heidelberg: Springer; 2007.

[33] Kalra MK, Maher MM, Toth TL, Hamberg LM, Blake MA, Shepard JA, et al. Strategies for CT radiation dose optimization. Radiology 2004;230:619-28.

[34] Kalra MK, Maher MM, Rizzo S, Kanarek D, Shephard J-AO. Radiation exposure from Chest CT: issues and Strategies. J Korean Med Sci. 2004;19:159-66.

[35] General electric healthcare. Volume CT. GE Healthcare Publication; 2004.
[36] Barrett HH, Swindell W. Radiological imaging. New York: Academic Press; 1981.

[37] LightSpeed ${ }^{T M}$ VCT technical reference manual. Milwaukee, WI: GE Medical Systems; 2010.

[38] Bushberg JT, Setbert JA, Letdholdt EM, Boon JM. The essential physics of medical imaging. 2nd ed. Lippincott Williams \& Wilkins; 2002.

[39] Gagne RM, Quinn PW, Jennings RJ. Comparison of beam hardening and K-edge filters for imaging barium and iodine during fluoroscopy. Med Phys 1994;21:107-21.

[40] Tapiovaara MJ, Sandborg M, Dance DR. A search for improved technique factors in paediatric fluoroscopy. Phys Med Biol. 1999;44:537-59.

[41] Toth TL. Dose reduction opportunities for CT scanners. Pediatr Radiol 2002;32:261-7.

[42] Behrmana RH. The impact of increased Al filtration on X-ray tube loading and image quality in diagnostic radiology. Med Phys 2003;30.

[43] Chesler DA, Riederer SJ, Pelc NJ. Noise due to photon counting statistics in computed X-ray tomography. J Comput Assist Tomogr 1977;1:64-74.

[44] Huda W, Sterzik A, Tipnis S. X-ray beam filtration, dosimetry phantom size and CT patient dose conversion factors. Phys Med Biol 2010;55:551-61.

[45] Dixon RL. A new look at CT dose measurement: beyond CTDI. Med Phys 2003;30:1272-80.

[46] De Man B, Nuyts J, Dupont P, Marchal G, Suetens P. An iterative maximum-likelihood polychromatic algorithm for CT. IEEE Trans Med Imag 2001;20:999-1008.

[47] Marin D, Nelson RC, Schindera ST, Richard S, Youngblood RS, Yoshizumi TT, et al. Low-tube-voltage, high-tube-current multidetector abdominal CT: improved image quality and decreased radiation dose with adaptive statistical iterative reconstruction algorithm - initial clinical experience. Radiology 2010;254:145-53. 